distance below the plane of the ring and in a line nearly perpendicular to it.

No great accuracy is claimed for the angular measurements given above, but they are sufficient to show that the two features characteristic of conical refraction, namely, a curved wave-front and a particular state of polarization, appear soon after the acute bisectrix is passed and become progressively more complete and intense as we approach an optic axis. The Fresnel wave-surface accounts for a sudden change from point contact to circular contact of a tangent plane, but some modification of it seems necessary to account for a progressive change : what form this modification should take it is difficult to see.

After considering the subject of conical refraction, Stokes concluded: "We see, therefore, that the limitation of the number of tangent planes to the wave-surface, which can be drawn in a given direction on one side of the centre, to two, or at the most three, is intimately bound up with the number of dimensions of space; so that the existence of the phenomenon of internal conical refraction is no proof of the truth of the particular form of wave-surface assigned by Fresnel rather than that to which some other theory would conduct ${ }^{3}$."

Clifford hoped that useful results would flow from the application of the elliptic geometry of space : "I am", he wrote in 1870, "endeavouring in a general way to explain the laws of double refraction on this hypothesis, but have not yet arrived at any results suificiently decisive to be communicated"."

No results are to be found among his published papers.

There is a rather obscure passage in Potter's paper suggesting the existence of a real focus outside the crystal, but it is doubtful whether this represents a record of observation or an inference from theory. Sir C. V. Raman has, however, recently obtained conclusive proof of its existence, and he finds that "the usual explanations of conical refraction do not go deep enough into the physical aspects of the problem"s.

Hamilton himself wrote to Lloyd on January 1 , 1833 : "It is much for theory to have predicted the facts of conical refraction, but I suspect that the exact laws of it depend on things as yet unknown"'

${ }^{1}$ Potter, R., Phil. Mag., 18, 343 (1841).

'Sorby, H. C., Min. Mag., 1, 193, Pl. vii, Fig. 10 (1877); ibid., 15, 189, Fig. 7 (1910).

3 Stokes, G. G., Rept. Brit. Assoc. for 1862, 253 (1863).

- Clifford, W. K., Proc. Camb. Phil. Soc., 2, 157 (1876); reprinted in "Mathematical Papers", 21 (1882).

'Raman, C. V., and Nedungadi, T. M. K., NATURE, 149, 553 (1942). "Graves, R. P., "Life of Sir William Rowan Hamilton", vol. 1, 630 (1882).

\section{CENTRAL SCIENTIFIC AND TECHNICAL BOARD}

A

MEETING was called by the Association of Scientific Workers on September 4 to discuss and support the proposals for a Central Scientific and Technical Board. These proposals had been the subject of a Motion on the Order Papers of the House of Commons for which, according to The Times of September 9, 126 signatures of members of Parliament had been obtained.

The papers and discussion at the meeting showed that more scientific workers and engineers consider that there is a real need for a Central Board to link science to the central direction of the War, and two main reasons were given. The first was that our scientific resources are not being used as e.ficiently as they should be. The question of duplication of work and the problem of those who consider that their work is not of immediate importance to the war effort, as well as the lack of consultation of technical staffs on technical questions affecting production, were all mentioned in this section. The second main contention was that as scientific and technical considerations permeate every sphere with which the War Cabinet must be concerned; that, as in fact science affects strategy and strategy must determine scientific development, it is essential that technical advice shall be immediately available to the War Cabinet.

Mr. A. L. Bacharach, in the chair, referred to the responsibilities facing the Association, not only to gain better conditions for scientific workers but also to improve the role of science in the community. Although the Association is a trade union, by virtue of the peculiar position enjoyed by science the Association has a moral obligation towards society, and cannot separate the status of scientific workers from the status of science.

Lord Strabolgi said that many of the present difficulties facing the United Nations are directly traceable to the fact that we have not yet begun to use fully the scientific man-power of the nation. In modern war, machinery and equipment have a tremendous importance and without them the bravest men are helpless. It is not a question of insufficient funds having been at the disposal of the Service Department but rather the question of the proper use of funds. He considers that only the Air Ministry has taken full advantage of science; not only has it got its own scientific departments but it has also drawn most freely on outside men of science. He paid a tribute to the rapidity with which the Admiralty has found remedies for new devices sprung upon us by the enemy, but holds nevertheless that the Admiralty suffers through being a closed department and not taking advantage of outside developments. We have greater scientific knowledge and experience in Great Britain than in the whole of the Axis Powers: it is only waiting to be used.

Mr. Swann, referring to the investigations made by the Association into conditions in industry and Government service, said these showed conclusively that in a number of important respects the scientific and technical resources of the country were not being used to the full in the war effort. In its proposals for improving the position the Association has received support from many other bodies and a number of detailed improvements have been made during the last six months. These have, however, not by any means fulfilled the stated need for better organization of scientific and technical workers.

Technology is concerned with the processes of manufacture and their improvement and is an essential factor in production itself. New developments are the constant concern of the research and development establishments under the Supply Ministries, in industry and the universities, and these developments need to be closely linked with production. Science is also concerned with the equipment when it is made, how it works in practice and what modifications are necessary. Science is also concerned with the community, its food, its health, its protection from air attack, etc. All these functions of science and technology are divided up in the 
various Government departments and industry ; yet all these functions are related, and all are affected by the main strategy of the War. Strategical considerations determine which scientific problems are the rnost important; and conversely, the strategy of the War may be changed by scientific developments.

There is a great need for a body of scientific men who can indicate what assistance science can give to the development of strategy, who can interpret in technical terms the requirements of the strategy decided upon, and who can co-ordinate the scientific and technical work in the various Government departments and in industry. Such a body would need to be a full-time body, in direct contact with the War Cabinet, and with powers to obtain all necessary information on the resources and problems in the scientific and technical field; with the authority to initiate programmes of work and to have direct access to working scientists and engineers. The Associa. tion's proposals for a Central Scientific and Technical Board included these functions and powers. Mr. Swann pointed out that while many non-technical people spoke of men of science as 'inventors" the problem of the individual inventor is a special one, and is already very well provided for. Only a small proportion of the scientific discoveries made in this or any other country are due to individuals working on their own; the majority of discoveries are made by teams of workers in research and development establishments, either in Government service or in industry. It is these people who provide the bulk of scientific workers in Great Britain and with whom we are concerned in discussions of planning.

Other speakers from the platform and those who joined in the discussion from the floor all contributed arguments demonstrating the need for central planning in their own fields of work. Mr. D. T. Waigh spoke for men of science in industry, who, he claimed, represent the great majority of our scientific man-power. The scientific and technical staff have a fund of initiative and use it wherever they can; but they are often frustrated in their efforts through the existence of overlapping, lack of consultation and the feeling that their work is not co-ordinated into an effective whole.

Dr. D. McClean spoke of the need for planning in the biological sciences. He mentioned the absurd and damaging distinction between academic institutes and commercial undertakings, many of which are doing first-rate research and are at present the only organizations capable of translating laboratory processes into large-scale production. Bodies such as the Medical Research Council and the Agricultural Research Council are doing excellent work in their own institutes and by subsidizing research as well; but have never accepted responsibility for directing the national effort in the medical, veterinary and agricultural fields.

Mr. Innes spoke of the difficulties encountered by operational research groups, which are in general doing such good work. He considers that there is a need for combination between the different branches of the Services to avoid overlapping and waste of energy. The groups do not get sufficient guidance as to what is required, and for the efficient prosecution of their work they need knowledge of the research and production development that is actually being carried out on military equipment. Any central body must have its roots in working scientists and there must be close liaison with the scientists working for the Forces. To the working scientist it appears that thera is not sufficient policy decision on how our scientific man-power should be used.

The day after the meeting reported above it was announced that three full-time scientific advisers had been appointed to the staff of the Ministry of Production (see Nature of September 12, p. 301). While the Association welcomes these appointments as a step to link science with production, it is certainly not clear from the o.ficial announcement whether the scope of activities of the three advisers will be wide enough to answer the demand for a Central Scientific and Technical Board. Questions which are bound to be asked are: what powers the advisers will have to get information and to put their recommendations into practice, whether it will be possible to extend their work to include the scientific and technical activities of the Service Departments and other Ministries outside the strict field of production, what the position of the Lord Privy Seal will be in supervising the work of these advisers, and their relationship with the War Cabinet and the Minister of Production. Until these and other questions are answered in practice, those who have supported the call for a Central Scientific and Technical Board will no doubt continue to voice their demands for something wider than the appointment of advisers to a single Minister.

\section{FORTHCOMING EVENTS}

\section{Saturday, September 26}

Society of Chemical Industry (JoINT Meeting of THE MaNCHESTER SECTION AND THE FOOD GROUP) (in the Reynolds Hall, College of Technology, Manchester), at 2.30 p.m.-Dr. L. H. Lampitt: "The Preservation of Foodstuffs".

\section{Monday, September 28}

SOCIETY OF CHEMICAL INDUSTRY (YORKSHIRE SECTION) (in the Chemistry Lecture Theatre, The University, Leeds), at 6 p.m.-

Thursday, October I

INSTITUTION OF Electrical Enginkers (at Savoy Place, Victoria Embankment, London, W.C.2), at 5.30 p.m.-Prof. C. L. Forteseue : Presidential Address.

Saturday, October 3

Grologists' Assoctation (at the Geological Society of London, Burlington House, Piccadilly, London, W.1), at 2.30 p.m.-Dr. David Burlington House, Piccadilly, London, W.1), at 2
Williams : "Mineral Resources of the U.S.S.R.".

\section{APPOINTMENTS VACANT}

Applications are invited for the following appointments on or before the dates mentioned:

Assistant Lecturen in CHFmistry - The Registrar, The University, Manchester 13 (September 30).

Principat Teacher of Enginegring (Mechanical and Elec'TRICAL) in the Technical College, Coatbridge-The Director of Education and Deputy County Clerk, Lanarkshire House, 191 Ingram Street, Glasgow, C.1 (October 2).

Teacher of Electrical ENGINEERING--The Principal, Wolverton Technical College, Wolverton, Bucks. (October 3).

Assista nt Lecturer in Mechanical Enarnegring-The Registrar, College of Technology, Manchester 1 (October 5).

LeCTURER IN Mechanical OR EleCtrical ENgINEering in the Cannock Chase Mining College-The Director (H), County Education Offices, Stafford (October 14).

Assistant Master to teach Machine Shop Practice, TheorETICAL AND PRACTCAL-The Principal for Further Education in Gillingham, Medway Technical College, Senior Departments, Gillingham.

LeCTURER (MaN OR WOMAN) IN MATHEMatics for the Junior Technical School for Boys-The Secretary, Woolwich Polytechnic, Woolwich, London, S.E.18.

STEWARD FOR ORgANIC CHEMISTRY DEPARTMENT-The Laboratory Superintendent, Chemistry Department, Imperial College of Seience and Technology, South Kensington, London, S.W.7. 